\title{
Recent Advances in Leber's Hereditary Optic Neuroretinopathy
}

\author{
EEVA NIKOSKELAINEN, * JOHANNA VILKKI, KIRSI HUOPONEN, MARJA-LIISA \\ SAVONTAUS
}

Turku, Finland

Leber's hereditary optic neuroretinopathy (LHON) is a hereditary condition characterised by bilateral acute or subacute visual loss in young otherwise healthy men. The mechanisim of inheritance of LHON, the fact that most affected are male, the unknown precipitating factors that result in the affection of a susceptible young man and the role of the unique fundus changes in the acute stage are some of the mysteries that have puzzled research workers since the disease was first described. ${ }^{1}$ This paper reports some recent advances in the genetics of LHON.

Genealogical studies have shown that the disease is a hereditary condition but it does not follow Mendelian rules. The condition is transmitted by carrier females; men never transmit the disease to their children. In the Finnish series, $95 \%$ of the daughters of women known to carry the disease are themselves carriers. ${ }^{2}$ Seedorff has studied Danish families and reported a carrier rate of up to $100 \%$. $^{3}$

Most genetic information is localised in the nucleus of cells but there is also some DNA in the mitochondria. Mitochondrial DNA (mtDNA) is received exclusively from the mother, the mtDNA from the father apparently degenerating after fertilisation. In 1981 Anderson and his co-workers published in Nature the complete sequence of the human mtDNA molecule. ${ }^{4}$ The molecule is about $16.5 \mathrm{~kb}$ long and circular. All proteins coded by the mitochondrial genes are components of the mitochondrial respiratory chain and oxidative phosphorylation system.

\section{Point Mutation in the Mitochondrial DNA}

Genealogical studies have generated the hypothesis that LHON is caused by a mutation in the mtDNA. The mitochondrial mode of inheritance is strongly supported by the recent identification of a mtDNA mutation associated with the disease. ${ }^{5}$ The mutation at nt 11778 identified by Wallace et al. converts an evolutionarily highly conserved arginine to a histidine in ND4, one of the seven subunits of NADH dehydrogenase encoded by mtDNA. This mutation has never been found in control individuals. The mutation in ND4 eliminates a SfaNI restriction site which gives a relatively rapid laboratory method of studying whether a person has this mutation or not.

\section{Heterogeneity in the Mitochondrial DNA}

We have screened 21 Finnish families with LHON for the presence or absence of the nt 11778 mutation. Eleven families have the mutation, but ten have not. ${ }^{6,7}$ Holt and colleagues recently reported that four out of their eight families with LHON have the nt 11778 mutation, ${ }^{8}$ while in the series of Foulds etal. $74 \%$ of patients with LHON have this mutation. ${ }^{9}$ These studies suggest that there must be alternative mtDNA mutations associated with the condition which we are searching for. The subunit ND4 has already been analysed and no additional mutations 
were detected. ${ }^{10}$ The sequencing of the other subunits of the mtDNA is in process.

Genetic heterogeneity may, to a certain extent, explain the observed interfamilial variation in the clinical picture and prognosis in LHON. Holt and colleagues reported that the nt 11778 mutation was associated with a poor prognosis for visual recovery ${ }^{9}$ and in the Finnish series the prognosis seemed to be worse and the penetrance higher in families with the nt 11778 mutation. Thus both the English and Finnish studies suggested that SfaNI loss mutation was associated with a poor prognosis while the families without this mutation seem to have a more favourable course of the disease.

\section{Heteroplasmy}

It had been thought that an individual has only one type of mtDNA, in other words, he is homoplasmic for mtDNA. MtDNA heteroplasmy-mixed population of normal and mutant mtDNA within an individual-has only recently been recognised in some families with LHON. ${ }^{6,8,11}$ It has been suggested that the relative proportions of mutant and normal mtDNA correlate with the risk of developing or transmitting the disease.

The relative proportions of mutant and normal mtDNA can shift markedly across generations. ${ }^{11,12}$ So-called sporadic cases of the disease seem to occur in patients who have heteroplasmic unaffected maternal relatives. This suggests that sporadic cases may be the result of a recent mutation that has become sufficiently enriched by mitotic segregation to result in clinical disease. ${ }^{13}$

Lott et al. have studied the mtDNA heteroplasmy in blood (mesoderm) and hair (ectoderm) and detected variation in the proportions of normal and mutant mtDNA in these tissues in one individual. So far it has not been possible to study the tissues mainly affected by the disease.

Heteroplasmy may partly explain the intrafamilial variability of the clinical expression which is commonly seen in LHON. However, heteroplasmy cannot be the complete answer. In our series there are two brothers who both have more than $90 \%$ of mutant mtDNA but only one is affected. ${ }^{12}$

\section{X-Chromosomal-Mitochondrial Interaction}

Genealogical data from several countries indicate a manifestation rate for optic atrophy of approximately $50 \%$ in males and only $20 \%$ in females. This suggests that the liability to develop optic atrophy may be determined by some nucleo-mitochondrial interaction. An mtDNA mutation may lead to optic atrophy when matched with a specific X-chromosomal allele. The other alleles of this liability gene combined with an mtDNA mutation would lead to milder manifestations (for example, only microangiopathy). To test this hypothesis we studied the linkage relationships between the occurrence of optic atrophy and X-chromosomal DNA markers. We used 14 DNA markers located throughout the $\mathrm{X}$-chromosome. The liability gene was assumed to be $\mathrm{X}$-linked recessive. A linkage was found to DXS7 locating in the short arm of the X-chromosome. ${ }^{14}$ The lod score was over three which means that the probability of linkage versus non-linkage is $1000: 1$. Interestingly other linkage studies have assigned the gene loci for three other hereditary eye diseases to the same chromosomal region.

The diagnosis of LHON is not always straightforward, particularly if the patient is not seen in the acute stage when the diagnostically important fundus changes are visible. It is complicated in cases when there seems to be only one affected individual in the family, or when the maternal relatives in the family are not available for examination. In these cases a test for the detection of the nt 11778 mutation is helpful because at least half of the families with LHON have this mutation. Heteroplasmy is still a perplexing phenomenon and more studies are needed for determining the significance of the heteroplasmy in genetic counselling. In the future, a mutation-specific DNA test pattern with allele-specific nucleotide probes may be available giving us an accurate diagnostic laboratory test and a new way to give genetic counselling to the families affected by the disease.

\footnotetext{
References

${ }^{1}$ Le ber T: Ue ber hereditaere und congenital-angelegte Sehnervenleiden. Graefes Arch Clin Exp Ophthalmol 1871, 2: 249-91.

${ }^{2}$ Nikoskelainen EK, Savontaus M-L, Wanne OP, Katila MJ, Nummelin KU: Leber's hereditary optic neuroretinopathy, a maternally inherited disease: a genealogical study in four pedigrees. Arch Ophthalmol 1987, 105: 665-71.
} 
${ }^{3}$ Seedorf T: The inheritance of Leber's disease: a genealogical follow-up study. Acta Ophthalmol 1985, 63: 135-45.

${ }^{4}$ Anderson S, Bankier AT, Barrell BG, Bruijin de $\mathrm{MH}$, Coulson AR, Drouin J, Eperon IC, Nierlich DP, Roe BA, Sanger F, Schreier PH, Smith AJH, Staden R, Young IG: Sequence and organisation of the human mitochondrial genome. Nature 1981, 290: 457-65.

${ }^{5}$ Wallace DC, Singh G, Lott MT, Hodge JA, Schurr TG, Lezza AMS, Elsas LJI, Nikoskelainen EK: Mitochondrial DNA mutation associated with Leber's hereditary optic neuroretinopathy. Science 1988, 242: 1427-30.

${ }^{6}$ Vilkki J, Savontaus M-L, Nikoskelainen EK: Genetic heterogeneity in Le ber hereditary optic neuroretinopathy revealed by mitochondrial DNA polymorphism. Am J Hum Genet 1989, 45: 206-11.

${ }^{7}$ Vilkki J: Mitochondrial inheritance in man. Genetics of Le ber hereditary optic neuroretinopathy. Doctoral Thesis, Reports from the Department of Biology, University of Turku, No. 23, 1990a.

${ }^{8}$ Holt IJ, Miller DH, Harding AE: Genetic heterogeneity and mitochondrial DNA heteroplasmy in Le ber's hereditary optic neuropathy. J Med Genet 1989, 26: 739-43.
${ }^{9}$ Foulds WS, Bronte-Stewart J, Poulton J: Abnormalities of mitochondria and of zinc metabolism in patients with Leber hereditary optic atrophy. VIII. International Neuro-Ophthalmology Symposium, Winchester 23-29 June 1990.

${ }^{10}$ Huoponen K, Vilkki J, Savontaus M-L, Aula P, Nikoskelainen EK: Leber disease: Exclusion of missense mutations in ND4 gene of mtDNA in half of the Finnish families. Genomics, (in press).

${ }^{11}$ Lott MT, Voljavec AS, Wallace DC: Variable genotype of Leber's hereditary optic neuropathy patients. Am J Ophthalmol 1990 109: 625-31.

${ }^{12}$ Vilkki J, Savontaus M-L, Nikoskelainen EK: Segregation of mitochondrial genomes in a heteroplasmic lineage with Leber hereditary optic neuroretinopathy. Am J Hum Genet 1990b, 47: 95-100.

${ }^{13}$ Newman NJ and Wallace DC: Mitochondria and Le ber's hereditary optic neuropathy. Am J Ophthalmol 1990, 109: 726-30.

${ }^{14}$ Vilkki J, Savontaus M-L, Aula P, Nikoskelainen EK: Optic atrophy in Leber hereditary optic neuroretinopathy is determined by an X-chromosomal gene closely linked to DXS7. Am J Hum Genet (in press). 